\title{
Archean surface-derived contamination in the plume source of the Paleoproterozoic Bushveld Large Igneous Province
}

\author{
G.M. BybeE ${ }^{\prime}$, B. HAYES ${ }^{2}$, N. MAgalhãeS ${ }^{34}$, A. \\ ZIRAKPARVAR ${ }^{s}$, J. FARQUHAR ${ }^{4}, N^{\prime}$. WU ${ }^{4}$, S. PENNISTON- \\ DORLAND ${ }^{4}$, M. FEINEMAN ${ }^{6}$, T. LEACH ${ }^{7}$
}

Univ. of the Witwatersrand; grant.bybee@wits.ac.za

Univ. of Johannesburg; bhayes@uj.ac.za

Univ. of Toronto; nivea.magalhaes@utoronto.ca

‘Univ. of Maryland; jfarquha@umd.edu,npwu@umd.edu, sarahpd@umd.edu

sak Ridge National Laboratory; zirakparvana@ornl.gov

•Penn State University; mdf12@psu.edu

Princeton University; travisls@princeton.edu

The 2.055 Ga Bushveld Large Igneous Province (BLIP) is a unique example of a plume-related Precambrian large igneous province, containing vast resources of metals, including $\mathrm{PGE}, \mathrm{Cr}$ and $\mathrm{Vd}$. The origin of its enigmatic metallogenesis is intertwined with debates about its magma source. The volume and composition of BLIP magmas demands derivation from the asthenospheric mantle, however, the contribution of lithospheric mantle and crust, especially to the metal endowment, is controversial. Hf-in-zircon and bulk-rock $S$ isotopes across the BLIP provide a time-integrated record of the $\mathrm{Hf}$ isotope composition of its magma sources, traces subsequent contaminants, and indicates the presence of pre-2.4 Ga material in the plume.

The 9-km-thick mafic-ultramafic layered intrusion of the BLIP, known as the Rustenburg Layered Suite (RLS), shows remarkably constant $\Delta^{33} \mathrm{~S}(\mathbf{0 . 1 3 7} \% \circ \pm \mathbf{0 . 0 2 5}$ $\%$ ) and Hf-in-zircon $\left(\varepsilon_{\text {нг, } 2.055 \text { Са }}=\mathbf{- 8 . 6} \pm 2.6\right)^{1}$ isotopic compositions. The latter demand contamination by 2.7 Ga aged Ventersdorp cumulate material beneath the Kaapvaal craton. This may explain the vast economic metal reserves of the RLS. In contrast, BLIP diorite intrusions at Marble Hall (on-craton) and Mahalapye (off-craton) show chondritic, deep-mantle-like Hf ( $\varepsilon_{\text {ні } 2,2,55 \text { са }}$ $=0$ to -2$)$ and high, non-zero $\Delta^{33} \mathrm{~S}\left(\Delta^{33} \mathrm{~S}=0.161\right.$ to $0.5 \%$ ). Non-zero $\Delta^{33} \mathrm{~S}$ values indicate the presence of recycled Archean surface material in the BLIP plume, similar to modern day OIB magmatism. Our results suggest that surface material recycling into the mantle source of large igneous provinces was operative in the Paleoproterozoic.

Zirakparvar et al. (2014) Lithos 168:1050 
This abstract is too long to be accepted for publication.

Please revise it so that it fits into the column on one page. 